\title{
A Fuzzy Delphi and Fuzzy AHP Application for Evaluating Online Game Selection
}

\author{
Jao-Hong Cheng, Shu-Wei Chen
}

Department of Information Management, National Yunlin University of Science and Technology, Yunlin, Taiwan

\begin{abstract}
The trend of playing online games as an online entertainment has rapidly proliferated worldwide. This paper examines critical factors related to the selection of online games. Taking content design and operations management into account, we identified 15 constructs in the literature survey. The fuzzy Delphi Method is used to evaluate the primary criteria collected from 20 heavy players in Taiwan and the Fuzzy Analytic Hierarchy Process employed to calculate the weights of these criteria so as to establish a fuzzy multi-criteria model of online game selection. The results indicate the greatest weight being placed on the dimension of online game selection, and the 11 critical criteria related to online game selection were: (1) scenario, (2) graphics, (3) sound/light effects, (4) interface, (5) access, (6) interactivity, (7) security, (8) reliability, (9) responsiveness, (10) assurance, and (11) empathy. This study may have a contribution to make in terms of understanding how online game companies can reinforce content design and operation quality in an attempt to achieve competitiveness.
\end{abstract}

Index Terms: Online game; game design, operations management; interactive entertainment; Fuzzy Delphi method (FDM); Fuzzy Analytic Hierarchy Process (FAHP)

(C) 2012 Published by MECS Publisher. Selection and/or peer review under responsibility of the International Conference on E-Business System and Education Technology

\section{Introduction}

According to a DFC Intelligence report the worldwide online game market is forecast to grow. DFC estimates that the online game market is expected to reach $\$ 13$ billion by 2011 , and exceed $\$ 20$ billion in 2015. Both online game development and its operation are a high risk investment that could cause companies to lose money on an investment or receive returns that are less than expected. Accordingly, participants' selection of an online game has become a critical issue in extending the online game market.

Many Taiwan online game companies take a 'no monthly fee' in order to attract players and sell 'virtual goods or props' to increase profit. By applying virtual items, online game players can enhance individual power and personalize their individual character and identity [1]. From this viewpoint, developing an enjoyable game

* Corresponding author.

E-mail address: ${ }^{a}$ jhcheng@yuntech.edu.tw, ${ }^{\mathrm{g}} \mathrm{g} 9723811 @$ yuntech.edu.tw 
element or satisfying players' needs has become important because they strengthens players' acceptance and build a company's competitiveness.

The aim of this study is discover a more complete collection of explanatory variables for online game selection. Thus, we investigated the perspective of heavy players to explore those criteria players take into account when choosing game. This study develops a player evaluation model that incorporates the selection criteria. It is believed that this model will contribute to the development and operation of online games by online game companies.

\section{Literature Review}

\section{A. Online game design}

The online game includes various different systems such as animation, sound and music, story, databases and servers [2]. Research indicates that the primary design factors for online games are: the convenience of the operator, the suitability of feedback, and the reality of the design $[3,4,5]$. However, few studies have investigated why people enjoy playing particular online games or which design features are most closely related to the selection of games by players. In this study, we chose to investigate four dimensions (scenario, graphics, sound/light effects, and interface) in online game selection.

\section{B. Online game operation quality}

Online game companies need to identify primary factors to recognize players' needs and attitudes for effectively enhancing customer satisfaction. The framework of online games is similar to the composition of information system (IS). With regard to the measurement of IS, previous research indicates that system quality, information quality and service quality are important determinants influencing online consumers' cognition [6, 7, 8]. The online game company needs to ensure system quality (e.g., network bandwidth and server stability) of a multiplayer game [9]. If a player is interested in a dynamic object managed by client, it will need to perform the necessary synchronization via the server to obtain the stated information. Additionally, the player is concerned with online game security and secure trading of electronic item trading. Accordingly, research has focused on the three factors of access, interactivity, and security to evaluate the online game's system quality.

The player who gains more accurate information about how to play the games tends to achieve the online game's goals and his experience flows more easily [3]. For precision in information, online game companies should provide the background story, an episode introduction, and manual playing games for users to understand the game, and they should manage the help desk efficiently when communicating with gamers through the official website $[3,4,5]$. In our study, information quality was assessed by four constructs: relevance, timeliness, responsibility, and scope of the online game's information.

Prior studies indicate a high quality of services is expected to increase customer satisfaction and create extra benefits for the company $[9,10]$. Service quality includes reliability, responsiveness, assurance, and empathy [10]. The online game firm can serve the tasks correctly and reliably, satisfy customers' needs and offer services on time, offer enough knowledge and make customers feel trust and confidence, and identify the customer and offer personal services. Accordingly, we chose the four service quality factors of reliability, responsiveness, assurance, and empathy to examine whether these factors affect online game selection.

\section{Methodology}

In this study, due to fuzziness existing in the decision-making process of evaluating online game selection by players, we decided to adopt the Fuzzy Delphi Method (FDM) to generate the primary evaluation criteria in online game selection, and employed the Fuzzy Analytic Hierarchy Process (FAHP) to calculate the weight of each individual criterion so as to establish the fuzzy multi-criteria model of online game selection. The four steps are elaborated below. 


\section{Extracting Constructs and Designing the Survey}

To develop the survey instrument, a pool of items was identified from the literature. The items were measured on a seven-point fuzzy semantic scale of "absolutely important", "very important", "important", "no comment", "unimportant", "very unimportant", and "absolutely unimportant". A pretest on the questionnaire comprising of 43 items was performed with the help of academic researchers. The pool of items were distributed on 15 critical constructs, including scenario, graphics, sound/light effects, interface, access, interactivity, security, relevance, timeliness, responsibility, scope, reliability, responsiveness, assurance, and empathy. All of the instrument's subscales are represented in column 1 and 2 of Table 1.

TABLE I. THE TRIANGUlaR FuZZY FUNCTION WITH RESPECT TO EVERY POTENTIAL VARIABLE

\begin{tabular}{|c|c|c|c|c|c|}
\hline Construct & Potential Variable & $\begin{array}{l}\text { The Most Conservative } \\
\text { Cognition } \\
(\min , \text { med, max) }\end{array}$ & $\begin{array}{l}\text { The Most Optimistic } \\
\text { Cognition } \\
\text { (min, med, max) }\end{array}$ & $\begin{array}{l}\text { The Median of } \\
\text { Gray Interval }\end{array}$ & $\begin{array}{l}\text { Important } \\
\text { Criterion }\end{array}$ \\
\hline \multirow[t]{3}{*}{ Scenario } & Game Rule & $40,65,90$ & $60,80,100$ & 72.5 & \\
\hline & Role Setting & $50,70,90$ & $70,85,100$ & 77.5 & \\
\hline & Back Story & $60,75,90$ & $80,90,100$ & 82.5 & V \\
\hline \multirow[t]{3}{*}{ Graphics } & Frame Quality & $60,75,90$ & $70,85,100$ & 80 & $\mathrm{~V}$ \\
\hline & Image Quality & $60,75,90$ & $70,85,100$ & 80 & $\mathrm{~V}$ \\
\hline & Background Setting & $60,75,90$ & $70,85,100$ & 80 & $\mathrm{~V}$ \\
\hline \multirow[t]{3}{*}{ Sound/Light Effects } & Sound Effect & $60,75,90$ & $70,85,100$ & 80 & $\mathrm{~V}$ \\
\hline & Music & $60,75,90$ & $80,90,100$ & 82.5 & $\mathrm{~V}$ \\
\hline & Light Effect & $60,75,90$ & $70,85,100$ & 80 & $\mathrm{~V}$ \\
\hline \multirow[t]{5}{*}{ Interface } & Text & $60,75,90$ & $80,90,100$ & 82.5 & $\mathrm{~V}$ \\
\hline & Language & $60,75,90$ & $70,85,100$ & 80 & V \\
\hline & Operation & $60,75,90$ & $70,85,100$ & 80 & $\mathrm{~V}$ \\
\hline & Players Interaction & $0,45,90$ & $10,55,100$ & 50 & \\
\hline & Ease of Use & $60,75,90$ & $80,90,100$ & 82.5 & $\mathrm{~V}$ \\
\hline \multirow[t]{3}{*}{ Relevance } & Reference & $40,65,90$ & $50,75,100$ & 70 & \\
\hline & Usefulness & $30,60,90$ & $40,70,100$ & 65 & \\
\hline & Propriety & $40,65,90$ & $50,75,100$ & 70 & \\
\hline \multirow[t]{3}{*}{ Timeliness } & Latest Information & $50,70,90$ & $70,85,100$ & 77.5 & \\
\hline & Update & $50,70,90$ & $70,85,100$ & 77.5 & \\
\hline & Immediate Information & $50,70,90$ & $70,85,100$ & 77.5 & \\
\hline \multirow[t]{3}{*}{ Responsibility } & Trustworthiness & $50,70,90$ & $70,85,100$ & 77.5 & \\
\hline & Validity Confidence & $50,70,90$ & $70,85,100$ & 77.5 & \\
\hline & Confidence & $50,70,90$ & $70,85,100$ & 77.5 & \\
\hline \multirow[t]{3}{*}{ Scope } & Completeness & $50,70,90$ & $70,85,100$ & 77.5 & \\
\hline & Clear Information & $50,70,90$ & $70,85,100$ & 77.5 & \\
\hline & Player Needs & $50,70,90$ & $70,85,100$ & 77.5 & \\
\hline \multirow[t]{3}{*}{ Access } & Server Connection & $60,75,90$ & $70,85,100$ & 80 & $\mathrm{~V}$ \\
\hline & Stable Server & $60,75,90$ & $70,85,100$ & 80 & $\mathrm{~V}$ \\
\hline & Connection Quality & $60,75,90$ & $80,90,100$ & 82.5 & $\mathrm{~V}$ \\
\hline \multirow[t]{2}{*}{ Interactivity } & Usability & $60,75,90$ & $80,90,100$ & 82.5 & $\mathrm{~V}$ \\
\hline & Group Communication & $50,70,90$ & $70,85,100$ & 77.5 & \\
\hline \multirow[t]{3}{*}{ Security } & Privacy & $60,75,90$ & $80,90,100$ & 82.5 & $\mathrm{~V}$ \\
\hline & Assets & $60,75,90$ & $80,90,100$ & 82.5 & $\mathrm{~V}$ \\
\hline & Freely Trade & $40,65,90$ & $60,80,100$ & 72.5 & \\
\hline \multirow[t]{2}{*}{ Reliability } & Reliable Solution & $50,70,90$ & $70,85,100$ & 77.5 & \\
\hline & Precise Solution & $60,75,90$ & $80,90,100$ & 82.5 & V \\
\hline \multirow[t]{2}{*}{ Responsiveness } & Personnel Response & $60,75,90$ & $80,90,100$ & 82.5 & $\mathrm{~V}$ \\
\hline & Immediate Service & $60,75,90$ & $80,90,100$ & 82.5 & $\mathrm{~V}$ \\
\hline \multirow[t]{3}{*}{ Assurance } & Reliable Personnel & $60,75,90$ & $80,90,100$ & 82.5 & $\mathrm{~V}$ \\
\hline & Politeness & $60,75,90$ & $80,90,100$ & 82.5 & $\mathrm{~V}$ \\
\hline & Professional Knowledge & $60,75,90$ & $80,90,100$ & 82.5 & $\mathrm{~V}$ \\
\hline \multirow[t]{2}{*}{ Empathy } & Care & $50,70,90$ & $70,85,100$ & 78 & \\
\hline & Personalized Services & $60,75,90$ & $80,90,100$ & 82.5 & V \\
\hline
\end{tabular}




\section{Choosing the Experts}

The 20 experts chosen were heavy online game players in Taiwan. They spend over 4 hrs per day playing online games and over NT\$500 per month. In order to ensure the consistency of data collection, the identical group of experts was adopted at both first and second stage as the subjects.

\section{E. Applying the FDM to Selecting Critical Evaluation Criteria}

\section{Step 1: Collecting the Experts' Opinions}

The selected experts assigned a relative importance to every collected variable with respect to 15 dimensions in order to confirm critical constructs as the evaluation criteria of online game selection.

\section{Step 2: Establishing the Triangular Fuzzy Function}

All experts' estimations were used to establish the triangular fuzzy function of each individual criterion through the process of FDM [11, 12]. The process is as follows:

(1) The elements of evaluation set were determined by expert questionnaires of online game selection. With a score of 100 and 0 along a continuum ranging from "absolutely important" to "absolutely unimportant", the elements of the evaluation set were quantified objectively through the treatment of FDM.

(2) The maximum of the interval value was the experts' most optimistic cognition of the quantitative score for the element, and the minimum of the interval value was the experts' most conservative cognition of the quantitative score for the element.

(3) Solving the minimum L, geometric mean M, and the maximum U of all experts' most optimistic cognition score for each individual element, along with the minimum 1 , geometric mean $\mathrm{m}$, and the cognition score for each individual element, respectively. Triangular fuzzy number $\mathrm{A}=(\mathrm{L}, \mathrm{M}, \mathrm{U})_{\mathrm{L}-\mathrm{R}}$ of all experts' most optimistic cognition for each individual element and triangular fuzzy number $\mathrm{a}=(\mathrm{l}, \mathrm{m}, \mathrm{u})_{\mathrm{L}-\mathrm{R}}$ of all experts' most conservative cognition for each individual element were established and are illustrated in Fig 1.

\section{Step 3: Analyzing the Value of the Triangular Fuzzy Function}

The Triangular Fuzzy Function with respect to every potential variable was established and is represented in Table 1.

\section{Step 4: Selecting Critical Evaluation Criteria}

When selecting the evaluation criteria, it was generally considered important if relative importance was greater than $80 \%$. To gain the criteria, we calculated the median of the gray interval for every potential variable and took $80 \%$ as the threshold to filter out those variables with the score of less than $80 \%$ on the median of the gray interval. Thus, totally 19 items were eliminated, and 24 important criteria were obtained to serve as primary evaluation criteria in online game selection. They are represented in Table 1.

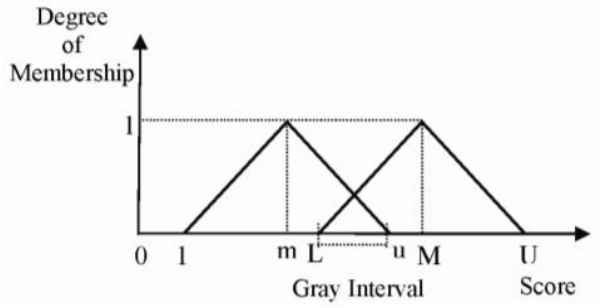

Figure 1. Triangular fuzzy number of the most optimistic cognition and the most conservative cognition 
TABLE II.

HiERARCHY STRUCtURE FOR EVALUATION CRITERIA IN ONLINE GAME SELECTION

\begin{tabular}{|c|c|c|c|c|c|c|}
\hline \multirow{2}{*}{$\begin{array}{c}\text { Level } 1 \\
\text { Goal }\end{array}$} & \multicolumn{3}{|c|}{ Level 2} & \multicolumn{3}{|c|}{ Level 3} \\
\hline & General Criterion & Weight & Rank & Subcriterion & Weight & Rank \\
\hline \multirow{24}{*}{$\begin{array}{l}\text { Evaluation } \\
\text { of } \\
\text { Online game } \\
\text { Selection }\end{array}$} & Scenario & 0.0704 & 11 & Back Story & 0.0704 & 6 \\
\hline & Graphics & 0.0871 & 6 & Frame Quality & 0.0130 & 21 \\
\hline & & & & Image Quality & 0.0334 & 10 \\
\hline & & & & Background Setting & 0.0407 & 9 \\
\hline & Sound/Light Effects & 0.1192 & 1 & Sound Effect & 0.0215 & 18 \\
\hline & & & & Music & 0.0240 & 16 \\
\hline & & & & Light Effect & 0.0737 & 5 \\
\hline & Interface & 0.0946 & 4 & Text & 0.0138 & 20 \\
\hline & & & & Language & 0.0237 & 17 \\
\hline & & & & Operation & 0.0247 & 14 \\
\hline & & & & Ease of Use & 0.0324 & 11 \\
\hline & Access & 0.0766 & 10 & Server Connection & 0.0255 & 13 \\
\hline & & & & Stable Server & 0.0255 & 13 \\
\hline & & & & Connection Quality & 0.0255 & 13 \\
\hline & Interactivity & 0.1142 & 2 & Usability & 0.1142 & 1 \\
\hline & Security & 0.0842 & 8 & Privacy & 0.0259 & 12 \\
\hline & & & & Assets & 0.0583 & 7 \\
\hline & Reliability & 0.0799 & 9 & Precise Solution & 0.0799 & 3 \\
\hline & Responsiveness & 0.0950 & 3 & Personnel Response & 0.0196 & 19 \\
\hline & & & & Immediate Service & 0.0754 & 4 \\
\hline & Assurance & 0.0866 & 7 & Reliable Personnel & 0.0113 & 22 \\
\hline & & & & Politeness & 0.0244 & 15 \\
\hline & & & & $\begin{array}{l}\text { Professional } \\
\text { Knowledge }\end{array}$ & 0.0509 & 8 \\
\hline & Empathy & 0.0923 & 5 & Personalized Services & 0.0923 & 2 \\
\hline
\end{tabular}

\section{F. Applying the FAHP to Calculate the Weight of each Criterion and each Subcriterion}

First, we built a hierarchical structure which included the ultimate goal at the top level, i.e. evaluation of online game selection, 11 general criteria at the second level, and 24 subordinate sub-criteria listed at the third level. The details of the hierarchical structure are represented in Table 2. Second, we used triangular fuzzy numbers to establish the pair-wise comparison matrix, and obtained the relative importance of paired criteria factors at level $n+1$ under the evaluation of criteria at level $n$ by individual expert's opinions. Third, we integrated the collected data of experts' opinions of each criterion by using the fuzzy average method. Fourth, we calculated the fuzzy weight of each criterion by using the Approximation Method developed by Buckley [13] and improved by Hsu [14]. Fifth, the Centroid Method was employed to defuzzying the weight of each evaluation criterion. Sixth, we normalized the obtained weights of all criteria. Finally, we calculated the synthesized weight for each evaluation criterion at the upper level. After that, the weights of all criteria at every level of the hierarchy could be obtained. The results are represented in Table 2.

\section{Results}

This study proves that online game scenario, graphics, sound/light effects, interface, access, interactivity, security, reliability, responsiveness, assurance, and empathy are the critical criteria in choosing online games. The results show that the highest priority criteria are sound/light effects (weight, 0.12), interactivity (weight, 0.11 ), and responsiveness (weight, 0.10). The findings explain the industrial properties of online games in the entertainment industry, which is high enjoyment industry, and continuity in player service for online game developers and operators. The results also indicate that subordinated evaluation criteria of a more relative importance are usability (weight, 0.11) and personalized services (weight, 0.09). The findings suggest that players are very concerned about game usability and service in terms of their individual needs. 


\section{Conclusions and suggestions}

Online game development and operation are viewed as critical tasks for game companies for deriving the maximum potential benefits in the entertainment market. The aim of this study was to offer an evaluation framework for online games, where such an evaluation framework is built through key criteria in the amusement environment. To address the decision problem, we utilized a FDM and FAHP to develop the criteria model in a fuzzy group multi-criteria decision making approach effective in extending the concept of the degree of optimality. Adopting the FDM and FAHP model, the criteria for online game selection are clearly identified and the problem is structured systematically. This helps decision makers to examine the strengths and weaknesses of the online game by comparing them with respect to appropriate criteria and sub-criteria. Results indicate that there are 24 sub-criteria in the 11 dimensions of online game selection.

Online game companies spend a huge amount of money on online game development and operations management. Based on the conductions, managers of online games are afraid that the game is not a favorite or popular game and this is circumstance they wish to avoid. The results indicate that the online game selection criteria that are most important are sound/light effect, interactivity, and responsiveness. This study contributes to extracting critical factors by providing a more comprehensive list of criteria in the selection of online games rather than only focusing on marketing ones and by estimating the relative importance of these constructs from the perspective of heavy players' views. This study can be used to facilitate the decision-making process in terms of the evaluation of online game selection by game design firms and operators. Our results can be referred to and research extended by developing more in-depth investigations. Other fuzzy multi-attribute decision-making methods can be used to build different evaluation models and then their results can be analyzed and compared.

\section{References}

[1] N. Ducheneaut, M. H. Wen, N. Yee, and G. Wadley, "Body and mind: A study of avatar personalization in three virtual worlds," Proceedings of the 27th international conference on Human factors in computing systems, Boston, MA, pp. 1151-1160, 2009.

[2] R. V. Kelly, Massively multiplayer online role-playing games: The people, the addiction and the playing experience. Jefferson, NC: McFarland \& Company, 2004.

[3] D. S. Choi, S. J. Park, and J. W. Kim, “A structured analysis model of customer loyalty in online games," Journal of MIS Research, vol. 11, pp. 1-20, 2001.

[4] N. H. Kim, S. C. Lee, and Y. H. Suh, "Strategy of market penetration in Japanese Internet market: Comparing online game loyalty between Korea and Japan with MSEM," Journal of the Korea Society for Quality Management, vol. 31, pp. 21-41, 2003.

[5] S. C. Lee, N. H. Kim, and Y. H. Suh, "The effect of flow and addiction upon satisfaction and customer loyalty in online games," Korean Management Review, vol. 32, pp. 1479-1501, 2003.

[6] W. H. DeLone and E. R. McLean, "Information system success: The quest for the dependent variable," Information Systems Research, Vol. 3, pp. 61-95, 1992.

[7] W. H. Delone and E. R. Mclean, "The Delone and Mclean of information system success: A ten-year update," Journal of Management Information System, vol. 19, pp. 9-30, 2003.

[8] S. Negash, T. Ryan, and M. Igbaria, "Quality and effectiveness in Web-based customer support systems," Information \& Management, vol. 40, pp. 757-768, 2003.

[9] L. Luo, J. Liu, L. Shao, W. Lu, and M. Ye, "A context-aware smart-call-center solution: Improving customer service for online games," IBM System Journal, vol. 45, pp. 145-160, 2006.

[10] W. Rodgers, S. Negash, and K. Suk, "The moderating effect of online experience on the antecedents and consequences of on-line satisfaction," Psychology \& Marketing, vol. 22, pp. 313-331, 2005. 
[11] A. Ishikawa, T. Amagasa, G. Tamizawa, R. Totsuta, and H. Mieno, "The Max-Min Delphi Method and Fuzzy Delphi Method via Fuzzy Integration,” Fuzzy Sets and Systems, vol. 55, pp. 241-253, 1993.

[12] J. H. Cheng, "The study of Asia-Pacific Port competitiveness and the core ability indicators," Journal of the Chinese Institute of Transportation, vol. 13, pp. 1-25, 2001.

[13] J. J. Buckley, "Fuzzy hierarchical analysis," Fuzzy Sets and Systems," vol. 17, pp. 233-247, 1985.

[14]T. H. Hsu, "The Fuzzy Delphi Analytic Hierarchy Process," Journal of Chinese Fuzzy Systems Association, Vol. 4, pp. 59-72, 1998. 